\title{
Delaying interference training has equivalent effects in various Pavlovian interference paradigms
}

\author{
Elizabeth J. Powell, Martha Escobar, ${ }^{1}$ and Whitney Kimble \\ Department of Psychology, Auburn University, Auburn, Alabama 36849-5214, USA
}

\begin{abstract}
Spontaneous recovery in extinction appears to be inversely related to the acquisition-to-extinction interval, but it remains unclear why this is the case. Rat subjects trained with one of three interference paradigms exhibited less spontaneous recovery of the original response after delayed than immediate interference, regardless of whether interference resulted in attenuated fear (extinction, CS-Shock followed by CS-noShock), acquisition of conditioned fear (latent inhibition, CSnoShock followed by CS-Shock), or acquisition of a response (counterconditioning, CS-Shock followed by CS-Sucrose). We suggest that delaying interference treatment increases the relative similarity of the interference and test contexts, facilitating retrieval of the interfering association and attenuating recovery of the original response.
\end{abstract}

[Supplemental material is available for this article.]

Various Pavlovian conditioning paradigms are instances of "retroactive interference between outcomes," in which recall of the association between a conditioned stimulus (CS) and unconditioned stimulus (US) is impaired when training of an association between the CS and a different US is interpolated between original training and testing (Bouton 1993; Miller and Escobar 2002; Escobar et al. 2004). For example, in "extinction" (Pavlov 1927), CS-Shock pairings (the original association) are followed by CS-noShock presentations (the interfering association), and responding is consistent with the interfering association. However, retroactive interference wanes with time, and the original association once again comes to control behavior, a phenomenon known as "spontaneous recovery" (Pavlov 1927; Rescorla 2004a).

According to recent reports, spontaneous recovery from extinction may be an inverse function of the original-interfering training (O-I) interval (Rescorla 2004b; Maren and Chang 2006; Woods and Bouton 2008; Chang and Maren 2009; Huff et al. 2009; Johnson et al. 2010; but see Myers et al. 2006; Norrholm et al. 2008; Schiller et al. 2008; Archbold et al. 2010; Johnson et al. 2010). However, why delaying extinction reduces spontaneous recovery is not fully understood. Maren and Chang (2006) reported that reducing fear prior to immediate extinction by reducing the number of CS-Shock pairings or conducting extinction in a novel context attenuated spontaneous recovery, whereas arousing fear prior to delayed extinction by delivering shocks in a novel context increased spontaneous recovery. Seemingly, entering extinction in a state of fear reduces the long-term effectiveness of extinction (Morris et al. 2005). However, immediate extinction also appears to be of low effectiveness in appetitive preparations (Rescorla 2004b; Woods and Bouton 2008), suggesting that a general state of anticipation of an outcome rather than fear may be the relevant variable. Immediate extinction also appears to be context-independent (Myers et al. 2006; Chang and Maren 2009), which may be interpreted as reflecting nonassociative decreases in responding that dissipate with time (e.g., habituation (Chang and Maren 2009).

We propose an alternative view based on differential retrieval of recently learned information, modulated by the O-I interval.

\section{${ }^{1}$ Corresponding author}

E-mail escobmc@auburn.edu

Article is online at http://www.learnmem.org/cgi/doi/10.1101/Im.030650.113.
Increasing the O-I interval both enhances the discriminability of the contexts of original and interference training, and makes the contexts of interference training and testing more similar due to their greater relative proximity. Consequently, the test context may better reactivate memories of interference training in the delayed than the immediate condition (Bouton 1993; Escobar et al. 2001), increasing the likelihood of observing retroactive interference (Pineño et al. 2000) independent of level of fear at the onset of interference training.

Other Pavlovian interference phenomena have the same basic structure as extinction, but differ on whether subjects enter the interference training phase in a state of fear, and whether interference training results in fear attenuation. For example, in the latent inhibition (LI) paradigm (CS-noShock, CS-Shock) (Lubow and Moore 1959), subjects enter the interference phase in a state of low fear, regardless of the duration of the O-I interval. Similarly, in the counterconditioning paradigm (CS-Shock, CS-Sucrose) (Sherrington 1947), subjects receiving immediate interference training enter Phase 2 in a state of high fear (due to the recent shock treatment) and acquire an appetitive response, precluding the development of CS habituation. The present studies investigate the impact of manipulating the O-I interval in extinction (Experiment 1), LI (Experiment 2), and counterconditioning (Experiment 3) to assess the following two specific possibilities. First, if the effects of the O-I interval are mostly due to receiving interference training in a state of heightened fear, LI should be insensitive to manipulations of the O-I interval (but see Aguado et al. 1994; Killcross et al. 1998). Second, if immediate extinction results in habituation to the CS rather than interference, counterconditioning should be insensitive to manipulations of the O-I interval. However, if delaying interference treatment increases the similarity between the interference and test contexts, more retroactive interference (less spontaneous recovery) should be observed after long than after short O-I intervals, regardless of whether interference treatment results in attenuated fear (extinction), fear (LI), or a response incompatible with fear (counterconditioning).

The subjects were male Sprague-Dawley rats. Subjects in Experiment 1 ( $n=32, \sim 60$-d old) were experimentally naïve and subjects in Experiments 2 and 3 ( $n=32 /$ study, $~ 95$-d old) had previously participated in unrelated studies, but were naïve to the apparatus and stimuli used in the present studies. Subjects were 
pair-housed in standard plastic cages on a 12:12-h light:dark cycle. In Experiments 1 and 2, water availability was restricted to $30 \mathrm{~min} / \mathrm{d}$ (food available ad libitum), and in Experiment 3, subjects were brought down and maintained at $85 \%$ of their free feeding weight (water available ad libitum). The apparatus were eight identical chambers $(30.5 \times 24.1 \times 21.0 \mathrm{~cm})$, housed in soundattenuation cubicles illuminated with $100-\mathrm{mA}$ houselights delivered at 28 VDC. Exhaust fans provided constant background noise (70 dB [A-scale]). The side walls of the chamber were made of aluminum sheet metal; the remaining walls and ceiling were made of clear polycarbonate. A grid floor made of 4.8-mm stainless-steel rods was used to deliver a scrambled footshock. Various auditory stimuli could be delivered at $10 \mathrm{~dB}$ (A-scale) above background. In Experiments 1 and 2, depressing a response lever was associated with delivery of $0.05-\mathrm{mL}$ droplets of water into a receptacle cup located inside a niche. In Experiment 3, automatic dispensers delivered two 45-mg sucrose pellets into the cup, and infrared photobeams recorded head entries into the niche.

In Experiment 1 (extinction) (Fig. 1), lever-pressing was trained in four 1-h autoshaping sessions with water reinforcement delivered on concurrent FT-5-min/FR-1 (Day 1), FR-1 (Days 2 and 3 ), and VI-20-sec (Day 4 and subsequent) schedules. On Day 5 (Delayed condition) or 6 (Immediate condition), all subjects received three pairings of $X$ (a 30-sec pulsating white noise) and a 0.85-mA, 0.5-sec footshock (ITI: $10 \mathrm{~min}$ ). After completion of the 24-min session, all animals were returned to their home cages. Either $12 \mathrm{~min}$ (Immediate condition) or $24 \mathrm{~h}$ (Delayed condition) after the last conditioning trial, the first extinction trial was delivered. Extinction animals were scheduled to receive $20 \mathrm{X}$ presentations (mean ITI: $3 \mathrm{~min}$ ) in a $67-\mathrm{min}$ session. However, due to a programming error, only 19 presentations occurred. Subjects in the Control condition received time-equivalent context exposure. Because shock treatment severely disrupts baseline behavior, on Day 8 (Day 7 was a no-treatment day) all subjects received a 60-min restabilization-of-baseline treatment. On Day 9 (72 h after

\begin{tabular}{llccc}
\hline Group & $\begin{array}{c}\text { Original } \\
\text { training }\end{array}$ & $\begin{array}{c}\text { Interpolation } \\
\text { delay }\end{array}$ & $\begin{array}{c}\text { Interpolated } \\
\text { training }\end{array}$ & Test \\
\hline Extinction-Immediate & $\mathrm{X}$-Shock & $12 \mathrm{~min}$ & $\mathrm{X}$-noShock & $\mathrm{X}$ \\
Control-Immediate & $\mathrm{X}$-Shock & $12 \mathrm{~min}$ & context only & $\mathrm{X}$ \\
Extinction-Delayed & $\mathrm{X}$-Shock & $24 \mathrm{~h}$ & $\mathrm{X}$-noShock & $\mathrm{X}$ \\
Control-Delayed & $\mathrm{X}$-Shock & $24 \mathrm{~h}$ & context only & $\mathrm{X}$ \\
\hline
\end{tabular}

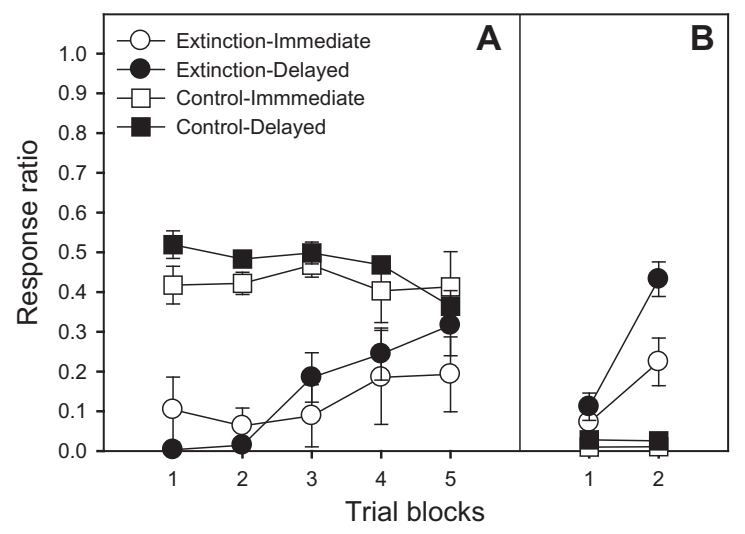

Figure 1. The table presents a summary of the design of Experiment 1. Panel $A$ presents mean response ratios ( \pm SEMs) over four-trial blocks for the interference (extinction) phase. Panel $B$ presents mean response ratios ( \pm SEMs) over three-trial blocks for the spontaneous recovery test, which occurred $72 \mathrm{~h}$ after extinction. Lower ratios reflect more response suppression (more fear), which is consistent with original (X-Shock) training, whereas higher ratios reflect less suppression (less fear), which is consistent with extinction (X-noShock) training (i.e., retroactive interference). extinction) all subjects were returned to the test chambers and received six presentations of X (ITI: $10 \mathrm{~min})$, to assess spontaneous recovery of fear.

For all measures, "response ratios" were calculated using the formula $A /(A+[B \div 3])$ (Annau and Kamin 1961), where $A$ and $B$ represent responding during the 30 -sec CS and a 90 -sec baseline period, respectively. If both $A$ and $B$ were zero, response ratios were incalculable. Acquisition of the Phase 2 contingency was analyzed using repeated measures analyses; for these analyses, missing scores were estimated as the average of the adjacent scores. If replacement was not possible, the subject was excluded from the analyses. Because all subjects continued to receive their scheduled treatment, their data were not excluded from the spontaneous recovery analyses. (Details on data management are presented in the Supplemental Materials.) Significance was established at alpha $<0.05$.

Extinction was analyzed with a 2 (condition: extinction vs. control) $\times 2$ (delay) $\times 5$ (four-trial block) ANOVA, which revealed a main effect of condition, $F_{(1,23)}=73.66$, a main effect of block, and a Condition $\times$ Block interaction, $F^{\prime} \mathrm{s}_{(4,92)}=4.19$ and 11.06 , respectively. (note that the last block had only three trials). The main effect of delay and all interactions with this factor were not significant, all $F^{\prime}$ s $<1.26$, replicating previous observations from our laboratory that extinction progresses equivalently in the two delay conditions (Fig. 1A; Johnson et al. 2010; but see Maren and Chang 2006; Schiller et al. 2008; Woods and Bouton 2008). Spontaneous recovery was analyzed with a 2 (condition) $\times 2$ (delay) $\times 2$ (3-trial block) ANOVA, which revealed main effects of condition, delay, and block, $F^{\prime} s_{(1,27)}=42.48,6.03$, and 60.01, respectively, as well as interactions of Block $\times$ Condition, Block $\times$ Delay, and Block $\times$ Condition $\times$ Delay, $F^{\prime} \mathrm{s}_{(1,26)}=60.89,7.01$, and 7.56 , respectively. Thus, delaying extinction increased the likelihood of responding, consistent with recently acquired information (XnoShock; retroactive interference), whereas providing immediate extinction increased intrusions from distally acquired information (X-Shock; spontaneous recovery) (Fig. 1B).

Subjects in Experiment 2 (LI) (Fig. 2) had been previously trained on the lever-press response. Thus, on Day 1 , they received one 60-min session on the VI-20-sec schedule to reestablish baseline responding. On Day 2 (Delayed condition) or 3 (Immediate condition), subjects in the LI condition received 36 presentations of X (mean ITI: $2 \mathrm{~min}$ ) in a 75 -min session. Subjects in the Control condition received 36 equivalent presentations of nontarget stimulus A ( $\mathrm{X}$ and A were a $5000-\mathrm{Hz}$ tone and a $1500-\mathrm{Hz}$ pulsating tone, counterbalanced). Two minutes after the last stimulus presentation, subjects were returned to their home cages, and then returned to the test chambers for the conditioning phase. Conditioning consisted of six pairings of $\mathrm{X}$ and a $0.60-\mathrm{mA}, 0.5$-sec footshock (mean ITI: $5 \mathrm{~min}$ ), starting $12 \mathrm{~min}$ (Immediate condition) or $24 \mathrm{~h}$ (Delayed condition) after the last preexposure CS presentation (session duration: $45 \mathrm{~min}$ ). On Days 4 and 5, baseline was restabilized and, on Day 6 ( $72 \mathrm{~h}$ after conditioning), spontaneous recovery was assessed with six $\mathrm{X}$ presentations as described for Experiment 1.

Conditioning was analyzed with a 2 (condition: LI vs. control) $\times 2$ (delay) $\times 2$ (three-trial block) ANOVA, which revealed main effects of condition (indicative of retardation-ofacquisition in the LI groups) and block, and a Condition $\times$ Block interaction, $F^{\prime} \mathrm{s}_{(1,20)}=17.50,64.52$, and 26.43, respectively. As was the case with extinction, O-I interval did not have an effect on acquisition of the Phase 2 contingency (Fig. 2A). Spontaneous recovery was assessed with a 2 (condition) $\times 2$ (delay) $\times 2$ (3-trial block) ANOVA, which revealed main effects of condition and block, and a Condition $\times$ Delay interaction, $F^{\prime} \mathrm{s}_{(1,25)}=4.28$, 25.28 , and 4.27 , respectively. The effect of delay was marginal, $F_{(1,25)}=3.88, P<0.061$. Thus, delaying conditioning increased 


\begin{tabular}{lcccc}
\hline Group & $\begin{array}{c}\text { Original } \\
\text { training }\end{array}$ & $\begin{array}{c}\text { Interpolation } \\
\text { delay }\end{array}$ & $\begin{array}{c}\text { Interpolated } \\
\text { training }\end{array}$ & Test \\
\hline LI-Immediate & $\mathrm{X}$-noShock & $12 \mathrm{~min}$ & $\mathrm{X}$-Shock & $\mathrm{X}$ \\
Control-Immediate & $\mathrm{A}$-noShock & $12 \mathrm{~min}$ & $\mathrm{X}$-Shock & $\mathrm{X}$ \\
LI-Delayed & $\mathrm{X}$-noShock & $24 \mathrm{~h}$ & $\mathrm{X}$-Shock & $\mathrm{X}$ \\
Control-Delayed & $\mathrm{A}-$-noShock & $24 \mathrm{~h}$ & $\mathrm{X}$-Shock & $\mathrm{X}$ \\
\hline
\end{tabular}

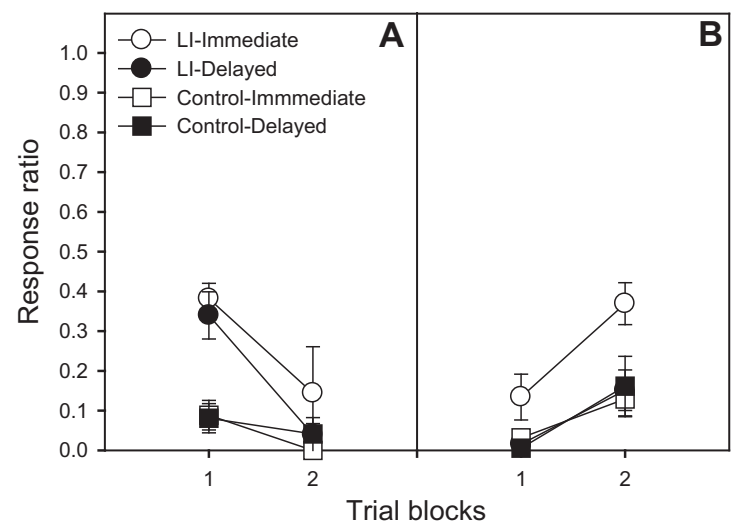

Figure 2. The table presents a summary of the design of Experiment 2. Panel $A$ presents mean response ratios ( \pm SEMs) over three-trial blocks for the interference (acquisition) phase of the latent inhibition (LI) paradigm. Panel $B$ presents mean response ratios ( \pm SEMs) over three-trial blocks for the spontaneous recovery test, which occurred $72 \mathrm{~h}$ after acquisition. Higher ratios reflect less response suppression (less fear), which is consistent with original (X-noShock) training, whereas lower ratios reflect more suppression (more fear), which is consistent with conditioning (X-Shock; i.e., retroactive interference).

responding, consistent with recently acquired information (XShock; retroactive interference), whereas providing immediate conditioning increased intrusions from distally acquired information (X-noShock), even if those distal memories did not evoke conditioned fear (Fig. 2B).

In Experiment 3 (counterconditioning) (Fig. 3), all subjects were trained on Day 1 to insert their heads into the food cull to obtain sucrose reinforcement delivered on a FT-4-min schedule during a 1-h session. On Day 2 (Delayed condition) or 3 (Immediate condition), subjects in the counterconditioning (CC) condition received three pairings of $\mathrm{X}$ (a white noise) and a $0.60-\mathrm{mA}, 1-\mathrm{sec}$ footshock (ITI: $10 \mathrm{~min}$; session duration: 25 min). Subjects in the Control condition received equivalent unpaired presentations of $\mathrm{X}$ and the shock (mean ITI: $5 \mathrm{~min}$ ). Although this control condition does not allow for a dissociation of the effects of extinction and counterconditioning, it was selected to provide a no-fear baseline against which to compare the effectiveness of counterconditioning training. Two minutes after the last stimulus presentation, all subjects were returned to their home cages. Then, either $12 \mathrm{~min}$ (Immediate condition) or $24 \mathrm{~h}$ (Delayed condition) after the last conditioning trial, all subjects received $20 \mathrm{X}$-Sucrose pairings (mean ITI: $3 \mathrm{~min}$ ) in a 70-min session. On Day 5 (72 h after counterconditioning [Day 4 was a no-treatment day]), spontaneous recovery was assessed with four presentations of X.

The two delay conditions acquired the X-sucrose contingency at an equivalent rate (Fig. 3A). A 2 (condition: CC vs. control) $\times$ 2 (delay) $\times 5$ (four-trial block) ANOVA revealed a main effect of condition, $F_{(1,28)}=24.12$ (indicative of retardation-of-acquisition in the CC groups), as well as a main effect of block and a Condition $\times$ Block interaction, $F^{\prime} \mathbf{s}_{(4,112)}=23.11$ and 5.65, respectively. Spontaneous recovery was assessed with a 2 (condition) $\times 2$ (delay) $\times 2$ (two-trial block) ANOVA, which revealed main effects of condition, delay, and block, as well as a Condition $\times$ Delay interaction, $F^{\prime} s_{(1,27)}=51.07,4.80,4.83$, and 6.35 , respectively.
Thus, consistent with the observations of Experiments 1 and 2, delaying counterconditioning increased responding, consistent with recently acquired information (X-sucrose; retroactive interference), whereas providing immediate counterconditioning increased intrusions from distally acquired information (X-footshock; spontaneous recovery) (Fig. 3B).

Temporal proximity between events can provide contextual information, and events that occur close in time can be encoded as part of a single "temporal context" (e.g., Bouton 1988, 1993). In the case of extinction, increasing the O-I interval can make the conditioning and extinction experiences be encoded in distinct temporal contexts. If testing occurs soon after extinction, the test and extinction contexts should be more temporally similar than the test and acquisition contexts, favoring retrieval of the extinction (X-noShock) contingency. Conversely, in the immediate condition, acquisition and extinction occur in close proximity and may be encoded as part of a single temporal context. Discriminability in terms of time may explain the observation of different levels of spontaneous recovery following immediate and delay extinction. For example, the "temporal weighting rule" (e.g., Devenport 1998) suggests that recent experiences are weighed more heavily than remote experiences (in this case, weight is equivalent to behavioral control). Thus, experiences that can be considered by the organism as relatively recent (the interfering association in the delayed condition) would be weighed more heavily than experiences that are more remote in time (the original association in the delayed condition). However, if the two experiences occur close in time (immediate condition), they would be weighed equally, and the recent experience would exert less behavioral control. Furthermore, the model assumes that, over time, the weight of an experience is discounted hyperbolically, meaning that experiences discount steeply first and then more slowly. That is, over time, recent and remote experiences come

\begin{tabular}{lcccc}
\hline Group & $\begin{array}{c}\text { Original } \\
\text { training }\end{array}$ & $\begin{array}{c}\text { Interpolation } \\
\text { delay }\end{array}$ & $\begin{array}{c}\text { Interpolated } \\
\text { training }\end{array}$ & Test \\
\hline CC-Immediate & $\mathrm{X}$-Shock & $12 \mathrm{~min}$ & $\mathrm{X}$-Sucrose & $\mathrm{X}$ \\
Control-Immediate & $\mathrm{X} /$ Shock & $12 \mathrm{~min}$ & $\mathrm{X}$-Sucrose & $\mathrm{X}$ \\
CC-Delayed & $\mathrm{X}$-Shock & $24 \mathrm{~h}$ & X-Sucrose & $\mathrm{X}$ \\
Control-Delayed & $\mathrm{X} /$ Shock & $24 \mathrm{~h}$ & X-Sucrose & $\mathrm{X}$ \\
\hline
\end{tabular}

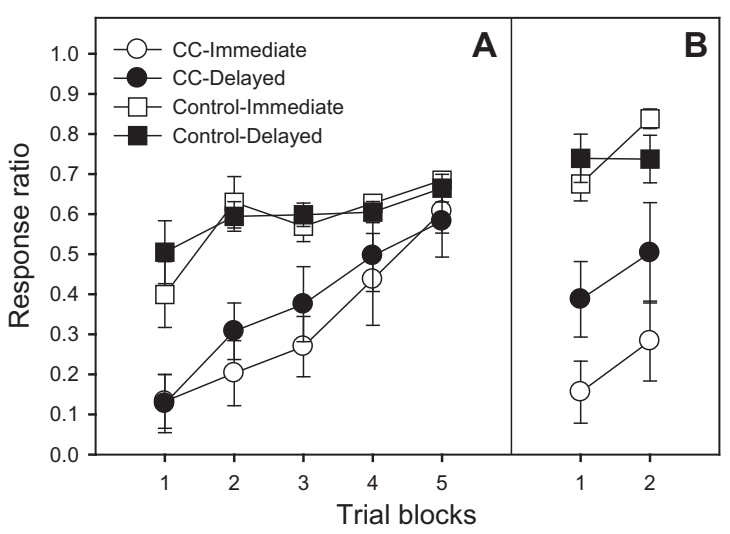

Figure 3. The table presents a summary of the design of Experiment 3. Dashes ('-') represent paired presentations whereas slashes $\left({ }^{\prime} /{ }^{\prime}\right)$ represent unpaired presentations. Panel $A$ presents mean response ratios ( \pm SEMs) over four-trial blocks for the interference (counterconditioning [CC]) phase of Experiment 3. Panel $B$ presents mean response ratios ( \pm SEMs) over two-trial blocks for the spontaneous recovery test, which occurred $48 \mathrm{~h}$ after CC treatment. Lower ratios reflect more response suppression (more fear), which is consistent with original (X-Shock) training, whereas higher ratios reflect less suppression (less fear), which is consistent with counterconditioning (X-Sucrose) training (i.e., retroactive interference). 
to be discounted to an equivalent weight. Previous data from our laboratory yield support for this perspective: If testing is delayed long after extinction, robust spontaneous recovery is observed after delayed extinction (Johnson et al. 2010). It remains to be seen whether a similar relationship holds for LI and counterconditioning.

Determining whether delaying interference treatment results in longer-lasting behavioral control than providing immediate interference treatment has important applied implications (see Johnson et al. 2010). Our observation that the O-I interval had similar effects in extinction and LI suggests that increasing the O-I interval does not reduce spontaneous recovery solely due to entering exposure treatment under low levels of fear. Furthermore, the observation that the O-I interval had similar effects in the counterconditioning preparation suggests that heightened spontaneous recovery after short O-I interval does not result solely from nonassociative processes (e.g., habituation) because an association was trained during the X-Sucrose pairings. These data are consistent with our view that the test context preferentially activated the more recently acquired information in the delayed condition, but this preferential activation was not observed in the immediate condition.

\section{Acknowledgments}

Support for this work is from National Institute of Mental Health grant R15 81269 to M.E. We thank Justin S. Johnson for assistance with data collection and manuscript preparation. We also thank Gregory Arnsdorff, Jessica Angel, and Daniel Krenn for their assistance with data collection.

\section{References}

Aguado L, Symonds M, Hall G. 1994. Interval between preexposure and test determines the magnitude of latent inhibition: Implications for an interference account. Anim Learn Behav 22: 188-194.

Annau Z, Kamin LJ. 1961. The conditioned emotional response as a function of intensity of the US. J Comp Physiol Psychol 54: $428-432$.

Archbold GEB, Bouton ME, Nader K. 2010. Evidence for the persistence of contextual fear memories following immediate extinction. Eur J Neurosci 31: 1303-1311.

Bouton ME. 1988. Context and ambiguity in the extinction of emotional learning: Implications for exposure therapy. Behav Res Ther 26: 137-149.

Bouton ME. 1993. Context, time, and memory retrieval in the interference paradigms of Pavlovian learning. Psychol Bull 114: 80-99.
Chang C-H, Maren S. 2009. Early extinction after fear conditioning yields a context-independent and short-term suppression of conditioned freezing in rats. Learn Mem 16: 62-68.

Devenport LD. 1998. Spontaneous recovery without interference: Why remembering is adaptive. Anim Learn Behav 26: 172-181.

Escobar M, Matute H, Miller RR. 2011. Cues trained apart compete for behavioral control in rats: Convergence with the associative interference literature. J Exp Psychol Gen 130: 97-115.

Escobar M, Arcediano F, Platt TL, Miller RR. 2004. Interference and time: A brief review and an integration. Rev Neurosci 15: 415-438.

Huff NC, Hernandez JA, Blanding NQ, LaBar KS. 2009. Delayed extinction attenuates conditioned fear renewal and spontaneous recovery in humans. Behav Neurosci 123: 834-843.

Johnson JS, Escobar M, Kimble WL. 2010. Long-term maintenance of immediate or delayed extinction is determined by the extinction-test interval. Learn Mem 17: 639-644.

Killcross AS, Kiernan MJ, Dwyer D, Westbrook RF. 1998. Effects of retention interval on latent inhibition and perceptual learning. Q J Exp Psychol 51B: $59-74$.

Lubow RE, Moore AU. 1959. Latent inhibition: The effect of nonreinforced pre-exposure to the conditional stimulus. J Comp Physiol Psychol 52: $415-419$.

Maren S, Chang C-H. 2006. Recent fear is resistant to extinction. Proc Natl Acad Sci 103: 18020-18025.

Miller RR, Escobar M. 2002. Associative interference between cues and between outcomes presented together and presented apart: An integration. Behav Process 57: 163-185.

Morris RW, Furlong TM, Westbrook RF. 2005. Recent exposure to a dangerous context impairs extinction and reinstates lost fear reactions. J Exp Psychol Anim Behav Process 31: 40-55.

Myers KM, Ressler KJ, Davis M. 2006. Different mechanisms of fear extinction dependent on length of time since fear acquisition. Learn Mem 13: 216-223.

Norrholm SD, Vervliet B, Jovanovic T, Boshoven W, Myers KM, Davis M, Rothbaum B, Duncan EJ. 2008. Timing of extinction relative to acquisition: A parametric analysis of fear extinction in humans. Behav Neurosci 122: 1016-1030.

Pavlov IP. 1927. Conditioned reflexes. Oxford University Press, London, England.

Pineño O, Ortega N, Matute H. 2000. The relative activation of the associations modulates interference between elementally trained cues. Learn Motiv 31: 128-152.

Rescorla RA. 2004a. Spontaneous recovery. Learn Mem 11: 501-509.

Rescorla RA. 2004b. Spontaneous recovery varies inversely with the training-extinction interval. Learn Behav 32: 401-408.

Schiller D, Cain CK, Curley NG, Schwartz JS, Stern SA, LeDoux JE, Phelps EA. 2008. Evidence for recovery of fear following immediate extinction in rats and humans. Learn Mem 15: 394-402.

Sherrington CS. 1947. The integrative action of the central nervous system. Cambridge University Press, Cambridge, UK.

Woods AM, Bouton ME. 2008. Immediate extinction causes a less durable loss of performance than delayed extinction following either fear or appetitive conditioning. Learn Mem 15: 909-920.

Received February 6, 2013; accepted in revised form March 5, 2013. 


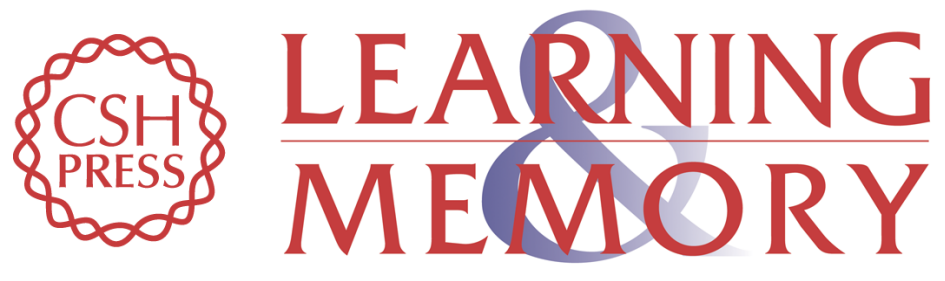

\section{Delaying interference training has equivalent effects in various Pavlovian interference paradigms}

Elizabeth J. Powell, Martha Escobar and Whitney Kimble

Learn. Mem. 2013, 20:

Access the most recent version at doi:10.1101/Im.030650.113

Supplemental http://learnmem.cshlp.org/content/suppl/2013/04/05/20.5.241.DC1
Material

References This article cites 23 articles, 7 of which can be accessed free at:

http://learnmem.cshlp.org/content/20/5/241.full.html\#ref-list-1

License

Email Alerting Receive free email alerts when new articles cite this article - sign up in the box at the Service top right corner of the article or click here. 